\title{
0 ESTADO PLURINACIONAL: Limites e Potencialidades de Refundação do Estado Moderno aPartir da Constituição Boliviana de 2009
}

Andriw de Souza Loch

Mestrando em Direitos Humanos e Sociedade pela Universidade do Extremo Sul Catarinense (Unesc). Membro do Núcleo de Pensamento Jurídico Crítico Latino-Americano, na linha de constitucionalismo crítico. andriwloch@gmail.com

\section{Lucas Machado Fagundes}

Doutor e mestre em Direito - Universidade Federal de Santa Catarina - UFSC. Pesquisador do Núcleo de Pensamento Jurídico Crítico Latino-Americano (coordenador da linha constitucionalismo crítico) - Unesc. Professor visitante do Mestrado em Direitos Humanos da Universidade Autônoma de San Luís de Potosí - UASLP, México. Professor do Mestrado em Direitos Humanos e Sociedade da Universidade do Extremo Sul Catarinense - Unesc. Imachado@unesc.net

\section{Resumo}

Trata-se de um estudo acerca do Estado plurinacional, tendo como objeto de pesquisa a Constituição Boliviana de 2009. A problemática central da investigação é a insuficiência da concepção moderna de Estado nacional em dar conta de realidades sociopolíticas complexas, por isso a hipótese de base é que o surgimento no texto constitucional boliviano da ideia de Estado plurinacional busca dar resposta a estas insuficiências. Dessa forma, o objetivo geral é investigar as possibilidades de mudança da plurinacionalidade na estrutura monista do Estado nacional e, especificamente, explorar alguns elementos no movimento da formação do Estado nacional moderno até as suas crises que possam dar sentido à refundação pelo viés plurinacional. Para este trabalho utilizou-se o método dedutivo baseado em pesquisas bibliográficas, que demonstraram a plurinacionalidade como uma alternativa ao modelo homogeneizador do Estado moderno, uma vez que busca se adequar às realidades existentes.

\section{Palavras-chave:}

Estado-nação. Modernidade. Homogeneidade. Constituição Boliviana. Estado plurinacional. 


\section{THE PLURINATIONAL STATE: LIMITS AND POTENTIALITIES OF REFUNDATION OF THE MODERN STATE SINCE THE BOLIVIAN CONSTITUTION OF 2009}

\section{Abstract}

It is a study of the plurinational State, having as object of research the Bolivian Constitution of 2009. The central problem of the investigation is the insufficiency of the modern conception of national State to account for complex socio-political realities, so the hypothesis it is based on the fact that the appearance in the Bolivian constitutional text of the idea of the Plurinational State seeks to respond to these shortcomings. In this way, the general objective is to investigate the possibilities of change of plurinationality in the monist structure of the national State, and specifically to explore some elements in the movement of the formation of the modern national state to its crises that may make sense to the refoundation by the Plurinational bias. For this work, we used the deductive method based on bibliographical research, which demonstrated the plurinationality as an alternative to the homogenizing model of the modern State, since it seeks to adapt to the existing realities.

\section{Keywords:}

Nation state. Modernity. Homogeneity. Bolivian Constitution. Plurinational State.

Recebido em: 22/6/2017

Aceito em: 1\%/6/2018

\section{Sumário:}

1 Introdução. 2 Dos Sistemas Jurídicos Pré-Modernos ao Estado Nacional Unificador. 3 Movimentos Nacionais na América Latina: a homogeneização elitizada da modernidade periférica. 40 Estado Plurinacional no Constitucionalismo Boliviano de 2009: limites e possibilidades. 5 Conclusão. 6 Referências. 


\section{INTRODUÇÃO}

O presente trabalho dedica-se a explorar o tema do Estado plurinacional na Constituição Boliviana de 2009 desde uma leitura do fenômeno Estado moderno. Assim, a questão envolve o fato de que a concepção de Estado-nação na modernidade não dá conta da realidade histórica concreta dos povos da região. Por este motivo, no ano de 2009 apresentou-se uma concepção de Estado plurinacional como potencialidade de refundaçáo a partir da perspectiva de unidade constitucional somada à diversidade de concepçóes nacionais, fortalecendo a ideia de Estado por meio da realidade concreta.

Por esta razão, a investigação prioriza, por meio de uma visão crítica, explorar, desde a consolidação e unificação do Estado moderno até a sua crise de legitimidade, os elementos que possam facilitar a compreensão do surgimento do Estado plurinacional como alternativa à realidade periférica regional. Assim, busca-se explorar os significados do processo de unificação como consolidaçáo da modernidade, por meio do sistema jurídico monista (atualmente em crise) e pela emergência da ideia de plurinacionalidade como possibilidade de refundação.

Para tanto, em um primeiro momento, será analisado o sistema jurídico pluralista - feudal e como ocorreu seu declínio e algumas de suas crises. A partir desse colapso na Idade Média será demonstrado como ocorreu a unificação da ideia de Estado e, especialmente, de que forma este fenômeno europeu refletiu-se na realidade periférica.

Na sequência analisar-se-á de que forma os movimentos de independência na América Latina, com ideais liberais e práticas controversas com o liberalismo europeu, serviram como instrumento legitimador de dominação dos povos originários, evidenciando, ao longo dos anos, a insuficiência do Estado-nação em atender às reais demandas das populaçôes e a necessidade de um novo modelo.

Por fim será investigada, em um terceiro momento, a emergência do Estado plurinacional boliviano que surge das lutas dos grupos autóctones e subalternizados, apresentando, por meio de um processo constituinte, potencialidades de refundação e ressignificação do Estado moderno. 
Diante disso, a ideia central do texto é expor o resultado de uma pesquisa por método dedutivo, em que as insuficiências do Estado moderno como problemática são contornadas pelas potencialidades do Estado plurinacional como hipótese de resolução alternativa. A constitucionalização do Estado plurinacional em 2009 na Bolívia representa uma adequação da concepção moderna à realidade concreta, conforme será demonstrado nas linhas que seguem.

\section{DOS SISTEMAS JURÍDICOS PRÉ-MODERNOS AO ESTADO NACIONAL UNIFICADOR}

Os sistemas jurídicos feudais não tratavam o Direito como uma ciência rígida e predeterminada; era plural, e cada feudo possuía suas leis próprias, originadas a partir da sua história, baseada na agricultura e na relação de proteção mútua entre os que a ele se submetiam (WOLKMER, 2001). Entende-se que na Idade Média Central existia um pluralismo por meio da diversidade de poderes menores. Cada feudo possuía seu próprio Direito, as normas a serem seguidas não emanavam da vontade do príncipe ou dos interesses de determinadas classes, mas eram extraídas a partir da realidade local. $\mathrm{O}$ modelo comunitário, baseado no cultivo de terras, foi substituído pelo comércio, e de maneira lenta, mas incessante, emerge a figura do príncipe, e uma nova conexáo com o Direito vai sendo modelada, que passa a não mais ser voltado à comunidade e deixa de ser um processo identificado com a cultura e com a história locais. Este príncipe vai unificando o poder e tenderá a exteriorizar suas vontades como forma de necessidade do Estado. Assim, inicia-se uma longa trajetória que pouco a pouco tentará banir qualquer forma de pluralismo jurídico do cenário político do Estado (GROSSI, 2004).

Diferente do modelo feudal anteriormente vigente, o Estado moderno passa a centralizar o poder na figura do príncipe, que detém toda a autoridade sobre os súditos. A relação sociopolítica feudal fora substituída pelo absolutismo (nas versóes 
divina e racionalista), e as leis passam a valer para todos os súditos que estão sob a autoridade do monarca; tem-se entâo um centro político que passa emanar leis e progressivamente vai eliminando o pluralismo antes existente. ${ }^{1}$

Dentro desta perspectiva, soma-se uma mudança contínua no sistema econômico, que faz nascer uma classe cada vez mais empobrecida (a plebe) e possibilita o crescimento econômico dos comerciantes (a burguesia). Este último grupo, economicamente ativo, irá progressivamente assumir o protagonismo político, de início marginalizado, ainda sob o domínio da nobreza e do clero (CAPELLA, 2002).

A burguesia, detentora da maior parte das riquezas daquela época, mas politicamente à margem, almejava conquistar o poder de alguma forma, encontrando embasamento para tal principalmente na Revolução Francesa (devido às suas proporçóes), que tinha como objetivo a liberdade das regulamentaçóes estatais absolutas, sob o manto de um Estado em que o poder soberano não fosse o do rei. A maior preocupação dessa classe não era com a monarquia em si, mas com o controle político, pois acreditava que era o que fazia o Estado funcionar. Afirmam Durant e Durant (1967) que a classe média não estava preocupada com a democracia, mas desejava um governo constitucional em que as pessoas pudessem participar. O objetivo era ser livre das regulamentaçóes estatais e ao mesmo tempo limitar o poder do governante.

Desta forma, a soberania passa a ser definida como um poder juridicamente incontrastável, de conteúdo e aplicação de normas de forma coercitiva dentro de determinado espaço geográfico, atribuindo-se a ela características de: una, indivisível, inalienável e imprescritível (STRECK; MORAIS, 2012). Criou-se o que se chama de "soberania popular", em que esta fica adstrita ao voto, e assim decide-se quem representará o povo, diminuindo o efeito de qualquer outra classe social que não a própria burguesia em condiçôes concretas de chegar ao poder e exercê-lo.

1 Pensamos que, para aclarar este punto, es decisivo el elemento jurídico, y en particular el significado que asume la normación en el Estado absoluto. Se trata, en otras palabras, de valorar en qué medida las monarquías absolutas europeas se han sentido de verdad portadoras de un derecho expresión del principio de la soberanía, capaz en cuanto tal de producir la abrogación íntegra del derecho de los otros, es decir, de la pluralidad de ordenamientos y de derechos, de lugar y de estamento, extendidos por el territorio, que el Estado jurisdiccional racionalizaba y componía unitariamente pero no eliminaba (FIORAVANTI, 2004, p. 22). 
Partindo do pressuposto de que é impossível atender à vontade de todos os cidadáos, compreende-se que a pessoa eleita representará a vontade da maioria que o elegeu, ou a "vontade geral", entendendo-se que essa suposta maioria tratava-se da parcela da população detentora e possuidora dos direitos naturais passíveis de serem exigidos (CAPELLA, 2002).

O Estado emerge, afirma Bercovici (2013), fazendo uma aproximação ao pensamento de Sieyès sobre a sociedade econômica natural, como um ente que deve garantir a propriedade e a livre-circulação de mercadorias. A função constitucional do Estado é garantir o bom funcionamento da sociedade civil, desenvolvendo a economia; é criado como solução pragmática, capaz de decidir sobre os problemas políticos de uma sociedade preocupada com a produção de riquezas. A naçáo moderna é uma instituição econômica fundada na hierarquia dos valores do mercado.

O surgimento dos Estados-nação é atribuído principalmente à modernidade, caracterizada pela formação de um tipo de Estado que possui o monopólio do que afirma ser o uso legítimo da força dentro de determinado território, buscando unir o povo submetido a seu governo por meio da homogeneizaçáo, criando uma cultura, símbolos e tradiçóes, ou inventando-os (HOBSBAWM, 2011). O Estado-nação surgiu com caráter liberal e civilizatório ao confirmar a existência de heterogeneidade, mas não aceitava a possibilidade de diversas naçóes em um território livre. Atribuía-se esta liberdade ao conceito de um Estado regido por leis, acreditando, portanto, que fosse possível reconhecer esta pluralidade aos "selvagens", defendendo ainda o interesse do governo em transformar essas comunidades em instituiçóes livres, transformando seus membros em instrumentos de dominaçáo sobre outros (MILL, 1981).

Nas palavras de Eros Grau (2010, p. 30), duas manifestaçóes podem caracterizar a centralização jurídica e política da modernidade: calculabilidade e previsibilidade, as quais garantiram ao mercado a segurança jurídica necessária para o desenvolvimento econômico, assegurado também por um sistema político concentrado, com a soberania nas mãos do Estado unitário.

O Estado moderno, portanto, e sua ideia de nação homogeneizadora, cumpriram a missáo de unificar o poder e o Direito, sem, no entanto, considerar as realidades complexas. Cabe também referir que na história do Estado moderno 
é lenta a evolução, por séculos, no sentido da unidade e da concentração do poder, ademais de ser consolidado como um movimento de construção de uma classe social emergente. A formação e o desenvolvimento do Estado na Europa, entretanto, sáo condicionantes daquele contexto, fato que se deu de forma diferenciada na América Latina. ${ }^{2}$

\section{MOVIMENTOS NACIONAIS NA AMÉRICA LATINA: A Homogeneização Elitizada da Modernidade Periférica}

Sob o ideal das elites político-econômicas regionais desenvolveram-se os movimentos de independência na América Latina. Seguiu-se a linha da unicidade imposta pelos dominadores e colonizadores europeus como perspectiva de sustentação do Estado moderno na periferia, que percebia a diversidade como um risco de revoltas e ameaça aos poderes constituídos. A unificação do poder do Estado foi um processo de reprodução da colonialidade na órbita interna dos países independentes, e a hegemonia política foi construída sobre os grupos que não pertenciam às classes dominantes. Assim, para dar legitimidade, criaram-se então símbolos, cultura jurídica e política desde a égide do poder do Estado, de forma que todas as naçóes tivessem algo em comum para compartilhar (idioma, bandeira, cultura e sentimento nacional).

Diante disso, as novas naçóes latino-americanas cresciam sob o ideal iluminista abstrato, pautado pela liberdade (como autonomia individual) e pela propriedade privada como garantia do exercício da cidadania e, evidentemente, os povos autóctones seriam deliberadamente excluídos e marginalizados pela criação de requisitos para ter sua cidadania reconhecida. $\mathrm{O}$ modelo de identidade nacional

\footnotetext{
2 "Contrariamente à construção do modelo estatal na Europa, legitimado por uma classe média liberal individualista, que transpóe o aparato aristocrático-feudal, a experiência de formação do Estado nas sociedades periférico-dependentes da América Latina adquire algumas particularidades distintas. Antes de tudo, há que se assinalar que o Estado não é produto de uma sociedade nacional e politicamente ordenada, muito menos da criação exclusiva de um segmento economicamente hegemônico, tampouco da sociodiversidade existente no continente, mas sim do próprio Estado como construtor, que irá ter a função privilegiada de assegurar a estratificação dos segmentos sociais e de modelar as sociedades nacionais existentes" (WOLKMER; MACHADO, 2013, p. 331).
} 
dos países latino-americanos foi uma ficção imposta aos habitantes por meio de dispositivos constitucionais elaborados por representantes das elites numericamente minoritárias.

Construiu-se assim uma categoria que Benedict Anderson (2008) denomina de "comunidade imaginada", a partir dos modelos coloniais e estabelecida pela imposição, controle e vigilância, garantindo a exclusão dos indivíduos não adaptáveis à situaçáo, ou insubordinados. Isto demonstra que, apesar de surgida dos processos de independência e ruptura das bases colonialistas que os ligava, a nova identidade dos países latino-americanos foi construída a partir da colonialidade, mantendo e reconfigurando as estruturas do sistema de dominação das populaçóes e grupos não pertencentes às elites. A partir desta perspectiva evidencia-se que, apesar de serem movimentos de independência para as camadas oprimidas, mantiveram-se as estruturas antes vigentes, servindo apenas como manutenção do poder das classes dominantes das colônias, que passaram então a ser chamadas de naçóes (LACERDA, 2014).

Em sentido parecido, o filósofo mexicano Luis Villoro (1997) destaca a necessidade de um novo modelo de Estado; não se trata de desfazer aquilo que se construiu a partir da modernidade, mas sim de desenhar um novo tipo de Estado condizente com as diferenças. É necessário que se tenha um Estado plural que não signifique a supressão das estruturas locais e a submissão cega a um mercado.

Tendo em mente esse contexto, os povos autóctones periféricos buscam libertar-se da dominação colonial ainda existente na América Latina. Percebeu-se que ao longo deste processo de formação nacional esses povos foram não apenas ingenuamente esquecidos, mas suprimidos da disputa do poder político e das tomadas de decisão. Esta situação não só os colocou à margem da modernidade, como impossibilitou-lhes viver de forma autônoma. A partir destes anseios, esses povos almejam um modelo constitucional democrático mais participativo e próximo das suas realidades, e têm como proposta mais revolucionária o Estado plurinacional.

O modelo de Estado plurinacional consiste numa virada descolonizadora, pois, se a colonização se baseia na unificação, a descolonização, conforme Yapur (2010), é justamente o contrário. Tal modelo pressupóe o reconhecimento da 
composição plural da sociedade, não como um acréscimo da institucionalidade estabelecida, mas como uma característica que particulariza e funda a própria institucionalidade dos povos. É este o sentido no qual se assenta a plurinacionalidade boliviana.

O processo de descolonização, afirma Clavero (2010), deve partir não apenas do dominador, mas também do dominado. Antes de qualquer coisa, significa uma transformação de pensamento, para que se saia do estado de servidáo mental. Os modelos de Constituição e de Estado atuais são insuficientes para explicar e perceber as demandas históricas dos sujeitos ocultados, pois, apesar de baseados em legalidade, não se amparam em legitimidade, que, na concepçáo de Fajardo (1997), é um critério subjetivo, que busca aprovação geral da população e aceitação da maioria, o que pode ser meramente formal quando feita por meio do voto, ou também mediante uma democracia participativa, que evidencia, percebe e reflete os interesses dos diferentes setores sociais da população.

Esta falta de legitimidade está diretamente ligada ao modelo de Estado e Constituição excludentes. Segundo Wolkmer e Machado (2013), esta negligência e falta foram cruciais para a tomada de consciência dos sujeitos ausentes, que, diante da segregaçâo e da evidência da crise, pensaram num novo modelo de constitucionalismo pautado na necessidade dos povos latino-americanos, trazendo como questáo central o Estado plurinacional. O objetivo, portanto, é a criação de um novo modelo de constitucionalismo participativo e transformador, diferente do que acontece nos sistemas modernos (excludentes e conservadores).

Santos (2010), todavia, ressalta que estas transformaçóes estão assentadas na força das mobilizaçóes sociais como forma de combater as visóes hegemônicas e democraticamente instituir visôes contra-hegemônicas. As instituiçôes hegemônicas representam a expressão da inércia das classes e ideias hegemônicas; são relaçóes sociais e campos de disputa, porém são assimétricas e desiguais. Por essa razão, a mobilização contra-hegemônica pressupóe a existência de um espaço-tempo alheio às instituições modernas, pois é neste campo que se fomentará a pressão contra a hegemonia. 
É pautado nisto que os povos autóctones empenham-se por sua autonomia dentro do Estado. Não se trata, como dito, do fim do Estado ou de um sistema que não possui leis, mas de uma forma de reconhecer essas populaçóes não mais como sujeitos frágeis, e sim como detentores de saberes diferentes, tấo válidos quanto aqueles estabelecidos pela modernidade.

Nesse sentido surge o que tem sido compreendido por diversos autores como a maior conquista do constitucionalismo contemporâneo: o Estado plurinacional. A vontade constituinte das classes populares, afirma Santos (2010), tem se manifestado no continente latino-americano, nas últimas décadas, por meio de intensas mobilizaçôes sociais e políticas.

Configura-se um constitucionalismo "desde abajo", protagonizado pelos excluídos e seus aliados, querendo expandir o campo político para além do horizonte liberal, por meio de uma nova institucionalidade, territorialidade, legalidade, regime político, novas subjetividades e individualidades. Tais mudanças representam meios de garantir políticas anticapitalistas e anticoloniais. Neste mesmo sentido, segue V. Garcés (2009), afirmando que estas novas Constituiçóes intentam, de acordo com a realidade de cada Estado, maior integração dos setores historicamente excluídos, como os povos indígenas.

[...] o Estado plurinacional é considerado como um modelo de organização política para descolonizar naçóes e povos indígenas originários, recuperar sua autonomia territorial, garantir o exercício pleno de todos os seus direitos como povos e exercer suas próprias formas de autogoverno. Um dos elementos fundamentais para a concretizaçáo do Estado plurinacional é o direito à terra, ao território e aos recursos naturais, com o objetivo de dar um fim ao latifúndio e à concentração de terras em poucas mãos, e de romper com o monopólio de controle dos recursos naturais em benefício de interesses privados. Do mesmo modo, para as organizaçóes do Pacto, o Estado Plurinacional implica que os poderes públicos tenham representação direta dos povos e naçóes indígenas, originários e camponeses de acordo com suas normas e procedimentos próprios (V. GARCÉS, 2009, p. 176).

O Estado plurinacional está inserido em uma nova forma de constitucionalismo e processo de descolonização totalmente diferente dos modelos conhecidos até então. Ele reconhece, dentro de um mesmo Estado, diversas naçóes, sistemas 
políticos, jurídicos e econômicos. Trata-se de uma nova forma de direito sustentada na plurinacionalidade, que, para Vargas (2009), é o ponto de ruptura com a regulação social e o ponto de partida para a libertação, com a construção de uma igualdade material e democrática. Apesar de ainda estar em desenvolvimento, já é possível afirmar que certamente este modelo é uma luta contra a colonialidade do poder e do saber e contra o capitalismo organizado em detrimento das periferias. Esse movimento e desenvolvimento emancipatório deve ser compreendido como um processo em andamento; náo há moldes ou garantias do resultado, uma vez que não está acabado. Trata-se de um constitucionalismo que busca atender às urgências das necessidades humanas e atender às exigências dos setores excluídos.

\section{ESTADO PLURINACIONAL NO CONSTITUCIONALISMO BOLIVIANO DE 2009: Limites e Possibilidades}

O Estado plurinacional, conforme mencionado, surge a partir de um constitucionalismo democrático, e pautado não no modelo liberal de igualdade, mas aceitando e principalmente reconhecendo as diferenças como essenciais às comunidades. Diante de tais necessidades, este sistema não significa simplesmente o reconhecimento constitucional da existência de inúmeras naçóes dentro de um mesmo Estado, mas está muito além. A plurinacionalidade é uma luta histórica que traz consigo diversas consequências e propostas de mudanças, inserindo-se em um contexto descolonizador de saberes e pensares; tem em seu cerne o pluralismo jurídico, o buen vivir, a autodeterminação dos povos, entre outras características.

É importante lembrar, contudo, que não se trata de uma estrutura completa e acabada, nem se pretende como tal. Diferentemente dos aparatos modernos, não possui característica imutável, mas se adapta às necessidades regionais, o que já demonstra significativo avanço, mas pode revelar-se também um sistema frágil, pois atua dentro do sistema dominador e almeja sua mudança interna. Enfim, trata-se de uma reforma endógena, e como tal precisa ser trabalhada com cuidado para poder atingir suas possibilidades, e não se transformar em um novo uso hegemônico do poder colonizador. 
A questão da plurinacionalidade na realidade periférica é nova, e provavelmente a que possui mais relevância nestas "novas" Constituições. A Bolívia, por exemplo, admite sua natureza intercultural e reconhece as várias nações entre as quais a Bolívia é a "Nação maior", para a qual convergem as outras nações originárias ou indígenas. A declaração de caráter plurinacional do Estado requer o reconhecimento de naçóes e povos em condições de sujeitos ausentes e coletivos.

Deve-se ter em conta que a plurinacionalidade não se esgota na matriz de reconhecimento de direitos políticos aos povos indígenas e sua articulação dentro do Estado, pois, se assim fosse, dificilmente representaria toda a mudança de paradigma do constitucionalismo. A expressão "Estado plurinacional" transformou-se em algo mais significativo do que sua simples morfologia literal de pluralidade de naçóes, porque amplia o debate para outras questóes, como o racismo e a falta de democracia (CLAVERO, 2010). O objetivo maior, conforme se perceberá na sequência, é o rompimento com as bases do sistema moderno:

A grande revolução do Estado plurinacional é o fato que este Estado constitucional, democrático, participativo e dialógico, pode finalmente romper com as bases teóricas e sociais do Estado nacional constitucional e democrático representativo (pouco democrático e nada representativo dos grupos não uniformizados), uniformizador de valores e logo radicalmente excludente. O Estado plurinacional reconhece a democracia participativa como base da democracia representativa e garante a existência de formas de constituição da família e da economia segundo os valores tradicionais dos diversos grupos sociais (étnicos e culturais) existentes (MAGALHÁES, 2009, p. 18).

Assim sendo, para Santos (2010), o mais importante não é que se chame plurinacional, mas sim que contribua para a consolidação das formas plurais de autogoverno, e possa desestruturar as matrizes liberais do sistema político monocultural e uninacional, criando a possibilidade da refundação do Estado.

Isto significa, para V. Garcés (2009), transformar pelo menos os seguintes âmbitos: 1 - Exercício do direito de autodeterminação e autonomias indígenas; 2 - Inclusão e redistribuição simultâneas, que permitam abolir a exclusão e a desigualdade; 3 - Direitos coletivos em, pelo menos, igualdade de hierarquia com os direitos 
individuais; 4 - Reconhecimento do pluralismo jurídico e, 5 - Redistribuição da propriedade da terra e do território. Tais mudanças, por consequência, significam alterar as estruturas que mantêm a forma estatal vigente.

O idioma oficial, os símbolos, os sistemas jurídico, político, cultural e econômico nasceram a partir das matrizes europeias. O Estado plurinacional, por sua vez, conforme Alcoreza (2012), supóe a transformação pluralista, intercultural e participativa dos instrumentos de gestão pública; é a condição política e a estrutura das transiçóes transformadoras das práticas políticas, democráticas e culturais, revelando-se um movimento flexível e de adequação às necessidades.

Para Santos (2007), o constitucionalismo plurinacional e intercultural tem de ser experimental, haja vista não ser possível resolver todas estas questóes latentes em uma Constituição. O autor usa o exemplo da África do Sul, que em 1994 deixou algumas questóes em aberto para serem resolvidas pela Constituinte de acordo com as necessidades, e teve excelentes resultados. Sob esta mesma ótica considera o processo de refundação algo aberto a possibilidades, uma vez que não existem receitas, nem soluçôes prévias, mas sim necessidades que vão se construindo dia a dia. Conforme corrobora o autor em outro momento:

En el contexto latinoamericano, la refundación del Estado pasa en algunos casos por el reconocimiento de la plurinacionalidad. Implica un desafío radical al concepto de Estado moderno que se asienta en la idea de nación cívica - concebida como el conjunto de los habitantes (no necesariamente residentes) de un cierto espacio geopolítico a quienes el Estado reconoce el estatuto de ciudadanos y, por lo tanto, en la idea de que en cada Estado sólo hay una nación: el Estado nación. La plurinacionalidad es una demanda por el reconocimiento de otro concepto de nación, la nación concebida como pertenencia común a una etnia, cultura o religión. En el lenguaje de los derechos humanos, la plurinacionalidad implica el reconocimiento de derechos colectivos de los grupos sociales en situaciones en que los derechos individuales de las personas que los integran resultan ineficaces para garantizar el reconocimiento y la persistencia de su identidad cultural o el fin de la discriminación social de que son víctimas (SANTOS, 2010, p. 81). 
Não se trata simplesmente de mudanças constitucionais ou legais, mas uma reforma estrutural, por isso fala-se em refundação. Neste câmbio radical, todavia, encontra-se um dos maiores desafios da plurinacionalidade: conseguir mudar o sistema internamente, sem, contudo, acabar com ele. Essa circunstância gera inúmeras críticas, especialmente para alguns setores sociais que não conseguem visualizar uma mudança a partir do próprio sistema estatal, pois este sempre foi e será um instrumento de dominação dos grupos privilegiados no poder.

O Estado-nação é instrumento da modernidade e não se está buscando sua extinção, mas a transformação das suas bases. Se os grupos que lutam por estas garantias não se mobilizarem cada vez mais para alcançar suas exigências, correm o risco de acabarem com um Estado plurinacional subordinado, convertendo as demandas e a autodeterminação dos povos em instrumento de colonialidade. Deve-se, a partir das demandas e lutas destes povos, conseguir com que o Estado aceite as modificaçôes necessárias.

Assim, não são os povos indígenas os que devem buscar formas de acomodar-se mais ou menos independentemente aos esforços de "modernização" do Estado; é, sim, o Estado que tem que "tolerar" as formas de autodeterminação dos povos indígenas sem fagocitá-los. Como o processo constituinte vem sendo apropriado pela classe política, é necessário agora fazer o trabalho de uma construção de autonomia "de baixo para cima". Desse modo, fica claro para o Estado plurinacional ser alcançado não na medida em que ele estiver consignado na Constituição mas, sim, na medida em que for mantida a mobilizaçáo social que deslanchou o processo constituinte [...] (V. GARCÉS, 2009, p. 185).

Ademais, os povos originários não possuem em seu seio a instituição estatal, mas conhecem-na por ter sido utilizada sempre como instrumento de colonização. Sendo assim, tem-se o receio de que a plurinacionalidade seja uma nova forma de manter as estruturas do poder, de favorecer as categorias mais fortes; afirma Tapia (2007) que, na Bolívia, as tribos indígenas não são unitárias entre si, pois apresentam diferenças políticas e sociais.

O Estado plurinacional traz ao debate a diferença entre as nações indígenas e a nação moderna, sem enfrentar, contudo, o problema da desigualdade no seio de cada um desses povos originários. Talvez mais pertinente que criar um Estado 
plurinacional, seria reconhecer a pluralidade de culturas no contexto de cada naçáo, prevalecendo desta forma a democracia, pois a História mostra que todos os tipos de nacionalismo produziram monopólios.

Certo é que a cultura de exploração resultou na insurgência dos povos originários e movimentos sociais, pretendendo um Estado e constitucionalismo mais justo, tendo como um de seus alicerces o Estado plurinacional. Assim sendo, talvez essa mobilização seja a maior revolução desses grupos, e também dessas Constituiçóes democráticas, buscando reconhecer e fomentar o direito à diversidade dos povos e naçôes. A experiência mais recente e mais aberta às questôes plurinacionais é a Constituição Política da Bolívia, de 2009.

Essa Constituiçáo reconhece o Estado boliviano como plurinacional, ${ }^{3}$ procura atingir as suas potencialidades e fazer frente as suas adversidades. Tal instrumento enfrenta diversas dificuldades, desde algumas críticas dos setores conservadores que lutam pela permanência dos instrumentos modernos de dominaçáo, até a resistência de povos originários e campesinos que não acreditam que a plurinacionalidade possa realmente ser ferramenta de mudança. Ante todas estas possibilidades e críticas, a plurinacionalidade boliviana é reconhecida desde 2009 e por esta razão serão feitas algumas análises acerca de sua aplicação, resultados e dificuldades.

O processo de desenvolvimento do sindicalismo campesino boliviano levou à vitória eleitoral um partido de origem campesina, o "MAS" (Movimento Ao Socialismo), que, de forma geral, opera como um partido dos trabalhadores. Sua chegada à Presidência tenta superar parte da não correspondência entre a configuraçáo cultural da sociedade boliviana e o grupo dominante. No Executivo existem pessoas provenientes do sindicalismo campesino de diversos lugares do país, bem como sindicatos de diversas origens, representantes de povos indígenas e profissionais de classe média. Pode-se destacar que a eleição do "MAS" mostra uma recomposição dos sujeitos governantes, possibilitando afirmar que essa relação de correspondência foi superada, porém ainda são necessárias modificaçôes no âmbito

3 Constitución Política del Estado Plurinacional de Bolivia: Art. 1º. Bolivia se constituye en un Estado Unitario Social de Derecho Plurinacional Comunitario, libre, independiente, soberano, democrático, intercultural, descentralizado y con autonomía. Bolivia se funda en la pluralidad y en el pluralismo político, económico, jurídico, cultural y lingüístico, dentro del proceso integrador del país. 
e nas relaçóes de poder das instituiçóes estatais, para que este constitucionalismo, e consequentemente o Estado plurinacional, possa atingir todo o seu potencial (CLAVERO, 2010).

Este modelo almeja transformaçóes, como uma nova organização territorial e forma de instituição política que valorize o ser humano, tanto em sua individualidade quanto em sua coletividade; logo, não se buscam mais os valores individuais do pensamento liberal europeu e segregador. A partir do reconhecimento e da valorização da coletividade, é possível perceber as diferenças e trabalhar a partir delas, com intuito de compreender não só o direito à igualdade, mas também o direito à diferença.

Dessa forma, dá-se um grande passo contra a colonialidade do poder, criando-se uma esfera de possibilidade de autonomia dos povos autóctones, estabelecida na própria Constituição:

La Constitución establece que "las entidades territoriales autónomas no estarán subordinadas entre ellas y tendrán igual rango constitucional” (art. 276). Es un pronunciamiento importante porque la propia tradición del constitucionalismo colonial de Bolivia hubiera fácilmente llevado al entendimiento supremacista de que las autonomías indígenas se subordinan a los Departamentos. No es así claramente, pero tal ecuación de autonomías debe interpretarse a la luz de los principios constitucionales y más particularmente del imperativo de la erradicación del colonialismo mediante al reconocimiento del derecho de libre determinación de los pueblos indígenas (CLAVERO, 2010, p. 103).

O reconhecimento destas pluralidades e a autodeterminação possibilitam o desenvolvimento de seus próprios sistemas econômicos, políticos, jurídicos e sociais de acordo com suas culturas, o que permite o desenvolvimento e o respeito à diferença. Estas conquistas não significam simplesmente a liberdade de desenvolvimento dentro da própria comunidade, mas a possibilidade de ampliação de participação democrática, diferente da cultura monista (FERNÁNDEZ, 2008).

Tais mudanças resultaram na incorporação por parte do Estado boliviano de princípios que pertencem à pluralidade de naçóes e povos existentes, conforme se extrai a partir da Constituição. 
Art. 8.1. El Estado asume y promueve como principios ético-morales de la sociedad plural: ama qhilla, ama llulla, ama suwa (no seas flojo, no seas mentiroso ni seas ladrón), suma qamaña (vivir bien), ñandereko (vida armoniosa), teko kavi (vida buena), ivi maraei (tierra sin mal) y qhapaj ñan (camino o vida noble) (BOLIVIA, 2009).

A Constituição plurinacional boliviana foi a primeira das Américas a fundar suas bases no acesso a direitos para todos e todas, adotando postura claramente anticolonialista; a primeira a romper expressamente os traços ainda restantes dos tempos da independência. Diz-se a primeira, pois outras Constituiçóes defendem o princípio da autodeterminaçáo baseado no mesmo direito que aprisionou estes povos, não significando de fato uma libertação. A Bolívia, por sua vez, não apenas reconhece constitucionalmente a persistência do colonialismo interno, como também prevê meios para sua erradicação definitiva, procedendo e conquistando, de fato, a refundação boliviana, a partir do Estado plurinacional. ${ }^{4}$

${ }^{4} \mathrm{Na}$ apresentação do texto constitucional boliviano, o presidente Evo Morales destaca esta demanda histórica: "Históricamente, Bolivia se ha construido a partir de la exclusión de los pueblos indígenas. Es por eso que en el marco de las transformaciones profundas y democráticas nos hemos propuesto cambiar esta situación injusta. Todos quienes nacimos en Bolivia somos originarios de esta tierra; algunos somos originarios milenarios y otros son originarios contemporáneos. El problema es que los originarios milenarios somos muchos, pero pobres y los originarios contemporáneos son pocos, pero ricos. Mediante esta Nueva Constitución Política queremos que todos los originarios bolivianos seamos iguales. Eso estamos buscando, sin racismo, ni discriminación. Hoy, con la Nueva Constitución Política del Estado tenemos la oportunidad histórica de cerrarle las puertas al racismo, a la discriminación y a la exclusión, empezando a construir un Estado plurinacional, intercultural y auténticamente democrático que se funde en la pluralidad cultural de nuestra patria. Para construir una Bolivia más justa necesitamos un golpe de timón de fondo y en esa tarea los pueblos indígenas nos señalan la ruta que debemos seguir. La Nueva Constitución establece que en el nuevo modelo de país los pueblos indígenas tendrán una profunda participación civil, política y económica. Para que nunca más seamos excluidos. Antes, las hermanas y hermanos quechuas, aymaras, guaraníes y otros hermanos de tierras bajas no podíamos entrar al Palacio, no podíamos entrar a la Plaza Murillo, no podíamos caminar en las aceras, en las ciudades importantes; ése es el pasado de los pueblos indígenas en Bolivia y en Latinoamérica. Ahora, los pueblos indígenas somos uno de los pilares fundamentales de un nuevo país. Estoy convencido de que la Nueva Constitución Política del Estado tiene que pasar del papel a la realidad para que nuestros conocimientos y nuestra participación nos ayuden a construir un nuevo futuro de esperanza para todos. Quién sino los pueblos indígenas podemos señalar el rumbo de estos cambios para la preservación de la naturaleza, para distribuir equitativamente los beneficios de los recursos naturales y de los territorios que habitamos ancestralmente. Sé que no es fácil el cambio cuando un sector extremadamente poderoso tiene que renunciar a sus privilegios. Vivimos un constante sabotaje porque estamos acabando con los privilegios para que todos podamos "Vivir Bien" y no mejor que nuestros semejantes. Sé que el cambio es muy difícil, pero tengo absoluta confianza en las bolivianas y bolivianos, en su capacidad de razonar, de aprender de sus errores, de recuperar sus raíces y de cambiar para forjar un país justo, diverso, inclusivo, equilibrado y armónico" (BOLIVIA, 2009, p. 4). 
Não obstante suas propostas de mudanças, o Estado plurinacional apresenta diversas críticas à sua estrutura. Trata-se de um modelo que possui o fim de refundar o Estado a partir de bases plurais e interculturais, simbolizando uma luta contra a hegemonia das formas modernas, porém sem as excluir do sistema vigente. Por consequência, segue sendo um caminho duvidoso quanto à real possibilidade de ampliação democrática e autonomia dos povos. Com base nestas questốes, serão analisadas algumas adversidades enfrentadas na Bolívia plurinacional que alguns autores afirmam não estar cumprindo com aquilo a que se propôs, conforme se afirma a seguir:

Una vez que se aprueba la Constitución Política del Estado por el 64 por ciento de los bolivianos, supuestamente debíamos esperar su cumplimiento. Esto significa, por lo menos dos cosas: la muerte del Estado-nación, que es la expresión colonial del Estado liberal y de la República, y la construcción del Estado plurinacional, comunitario y autónomo. Sin embargo, hasta la fecha, se ha hecho todo menos eso. Se ha restaurado al Estado-nación y su mapa institucional con sus normas y estructuras liberales. Así, en vez de descolonizarnos, estamos recolonizándonos (ALCOREZA, 2012, p. 410).

Percebe-se que, apesar das suas propostas, torna-se deficitário em alguns pontos, como a autodeterminação dos povos, que deveria ser regulamentada dentro do regime de cooperação e colaboração à vista do pluralismo jurídico, instrumentalizando harmoniosamente as questóes divergentes entre a justiça comum e indígena, sem interferir de qualquer forma na autonomia das comunidades. Foi editada, todavia, à base de tentativas de manipulação da opinião pública e deslegitimação da jurisdição dos povos originários e campesinos, o que resultou na imposição de alguns limites às culturas indígenas (FERRAZZO, 2015). Tal fato evidenciou dificuldades que já eram previsíveis na incorporação deste modelo.

Para Alcoreza (2012), uma das confusóes da formação do Estado plurinacional foi acreditar que o MAS seria o representante dos movimentos sociais. O MAS era visto como movimento cocaleiro e estava entre os mais conservadores e amparados pela antiga esquerda. Alguns de seus membros tinham projetos guerrilheiros, outros tinham projetos insurgentes e outros se limitavam a questôes eleitoreiras, mas de todas as maneiras os projetos correspondiam aos limites da velha esquerda, já superados pelos movimentos contra-hegemônicos. Apesar de todas estas críticas, 
em 2005 os movimentos sociais indígenas e campesinos se uniram, fazendo com que o MAS chegasse ao poder, porém sem atingir todas as demandas e promessas da refundação boliviana.

A aplicação do Estado plurinacional vem passando por diversas dificuldades, especialmente devido ao seu caráter transformador e reformador, que busca em seu seio a efetiva descolonização da América Latina. Estas dificuldades, todavia, não devem ser motivo para desacreditar da sua capacidade transformadora, haja vista que, conforme referido anteriormente, é um Estado experimental. O que tem sido apresentado pelo Estado plurinacional é novo, e a Bolívia vive algo totalmente inovador que não foi testado por nenhum outro país até então. Estas potencialidades geram expectativas de melhoria aos povos e comunidades, mantendo seu caráter flexível, intercultural, aproximando-se cada vez mais de uma democracia participativa.

\section{CONCLUSÃO}

O presente trabalho buscou elencar alguns elementos que importam na construção e na transformação do Estado e do Direito no cenário da modernidade, tendo como marco inicial o sistema jurídico feudal. Com isto, avançou-se para as revoluçóes liberais do século 18 , que operaram uma grande modificação no sentido monista, com o poder não mais concentrado nas mãos do monarca, mas na ideia de "soberania da nação" por meio de uma cultura liberal e individualista, que se legitimou com as leis do Estado nacional que tinha como escopo criar uma identidade unitária com base no espaço de terra determinado pelo próprio Estado, tratando-se de uma ficção, uma criação necessária para a manutenção do sistema.

Baseados neste mesmo ideal de libertação das revoluçôes liberais (especialmente na França e nos Estados Unidos da América), as elites criollas da América Latina passaram a buscar independência das metrópoles, para se tornarem naçóes autônomas e não mais centros administrativos. Estes movimentos, apesar de independentistas, não objetivavam libertar todos os povos da América espanhola, mas sim a classe que já era dominante nas colônias. Esta situação, todavia, atingiu sua 
crise no pós-Segunda Guerra Mundial, com o processo de emancipação dos povos e o progressivo avanço da globalização, servindo como estopim para a tomada de consciência dos povos oprimidos.

Esta tomada de consciência envolveu a busca por um processo de descolonizaçáo e um constitucionalismo transformador, destacando-se o Estado plurinacional, que intenta não só reconhecer a diversidade de naçóes existentes dentro de um mesmo Estado, mas lhes dar autonomia, a fim de que possam trabalhar e viver de acordo com as suas realidades. Este modelo teve sua efetivação mais recente na Constituição Boliviana de 2009. Tem-se um modelo que reconhece diversos princípios destes povos, mas que ainda enfrenta várias críticas quanto a sua efetivação. Deve-se ressaltar, contudo, que o Estado plurinacional, diferente do Estado e do constitucionalismo modernos, não se propóe rígido e imutável, mas tendente a sua adaptação de acordo com a realidade e necessidades dos povos.

Sendo assim, o Estado plurinacional que se apresenta na última Constituição Boliviana é uma demanda histórica de diversos setores sociais ausentes das tomadas de decisão em âmbito institucional. Logo, as mudanças que opera esta perspectiva no sistema estatal periférico dizem respeito ao modo da evolução do Estado como campo político de reprodução dos privilégios das elites política, econômica e socialmente dominantes.

Pode-se afirmar que o Estado plurinacional foi uma inovação institucional (jurídica e política) que visa a dar uma abertura concreta para que a ideia de nacionalidade estatal homogênea seja vista como incompleta, e possa finalmente, ao menos em termos iniciais, receber as outras nacionalidades como parte de uma unidade plural na sua composição, refundando o modelo unívoco e excludente do Estado-nação da modernidade periférica.

\section{REFERÊNCIAS}

ALCOREZA, Raúl Prada. Estado plurinacional comunitario autonómico y pluralismo jurídico. In: SANTOS, Boaventura de Sousa; EXENI RODRÍGUEZ, José Luis (Org.). Justicia indigena, plurinacionalidad e interculturalidad en Bolivia. 2. ed. Quito: Fundación Rosa Luxemburgo, 2012. p. 407-444. 
ANDERSON, Benedict: Comunidades imaginadas. São Paulo: Cia das Letras, 2008.

BEDIN, Gilmar Antonio. A Idade Média e o nascimento do Estado moderno: aspectos históricos e teóricos. 2. ed. Ijuí: Ed. Unijuí, 2013.

BERCOVICI, Gilberto. Soberania e constituição: para uma crítica do constitucionalismo. São Paulo: Quartier Latin, 2013.

BOLIVIA. Constitución Política del Estado. Gaceta Oficial de Bolivia, Edición Oficial, La Paz, Bolívia, feb. 2009.

CAPELLA, Juan Ramón. Fruto proibido: uma aproximação histórico-teórica ao estudo do Direito e do Estado. Porto Alegre: Livraria do Advogado, 2002.

CLAVERO, Bartolomé. Bolivia entre Constitucionalismo Colonial y Constitucionalismo Emancipatorio. In: VARGAS, Idón Moisés Chivi (Org.). Bolivia - Nueva Constitución Política del Estado: conceptos elementales para su desarrollo normativo. La Paz, Bolívia: Vicepresidencia del Estado Plurinacional, 2010. p. 97-108.

DURANT, Will; DURANT, Ariel. A história da civilização X: Rousseau e a revolução. Rio de Janeiro: Record, 1967. 1.038 p.

ELIAS, Norbert; JUNGMANN, Ruy. O processo civilizador. Rio de Janeiro: Jorge Zahar, 1993. $2 \mathrm{v}$.

FAJARDO, Raquel Yrigoyen. Una fractura original en América Latina: La necesidad de una juridicidad democrático-pluralista. In: BIRK, Fridolin. Guatemala: pobre, oprimida o Princesa Encantada. Guatemala: Fundación Friedich Ebert, 1997.

FERNÁNDEZ, Albert Noguera. Plurinacionalidad y autonomías. Comentarios en torno al nuevo proyecto de Constitución boliviana. Revista Española de Derecho Constitucional, Espanha, n. 84, 2008.

FERRAJOLI, Luigi. A soberania no mundo moderno: nascimento e crise do Estado nacional. 2. ed. São Paulo: Martins Fontes, 2007.

FERRAZZO, Débora. Pluralismo jurídico e descolonização constitucional na América Latina. 2015. 464 fl. Dissertação (Mestrado em Direito) - Universidade Federal de Santa Catarina, Florianópolis, 2015.

FIORAVANTI, Marizio (Coord.). El Estado en Europa: instituciones y derecho. Madrid: Trotta, 2004.

GRAU, Eros Roberto. A ordem econômica na Constituição de 1988. São Paulo: Malheiros, 2010 . 
GROSSI, Paolo. Mitologias juridicas da modernidade. Florianópolis: Fundação Boiteux, 2004.

GUIBERNAU, Montserrat. Nacionalismos: o Estado nacional e o nacionalismo no século XX. Rio de Janeiro: Jorge Zahar Ed., 1997.

HOBSBAWM, E. J. Naçôes e nacionalismo desde 1780: programa, mito e realidade. Rio de Janeiro: Paz e Terra, 2011.

HROCH, Miroslav. Do movimento nacional à nação plenamente formada: o processo de construção nacional na Europa. In: BALAKRISHNAN, Gopal (Org.). Um mapa da questão nacional - do Movimento Nacional à Nação Plenamente Formada: o processo de construção nacional na Europa. Rio de Janeiro: Contraponto, 2000. p. 85-106.

LACERDA, Roseane Freire. “Volveré, y seré Millones”: Contribuições Descoloniais dos Movimentos Indígenas Latino-Americanos para a Superação do Mito do Estado-Nação. 2014. 265 fl. Tese (Doutorado em Direito) - Universidade de Brasília, Brasília, 2014.

MACHADO, Lucas. Pluralismo jurídico e justiça comunitária na América Latina: perspectivas de emancipação social. 2011. 218 fl. Dissertação (Mestrado em Direito) - Universidade Federal de Santa Catarina, Florianópolis, 2011.

MAGALHÃES, José Luiz Quadros de. O Estado plurinacional na América Latina. Revista Democracia Digital e Governo Eletrônico: Busca Legis, Florianópolis, p. 1-25, abr. 2009. Disponível em: <http://egov.ufsc.br/portal/sites/default/files/anexos/30440-31724-1-PB. pdf>. Acesso em: 10 jan. 2017.

MILL, John Stuart. Consideraçōes sobre o governo representativo. Brasília: UnB, 1981.

PASTOR, Roberto Viciano; DALMAU, Rubén Martínez. El Nuevo Constitucionalismo Latinoamericano: Fundamentos Para una Construcción Doctrinal. Revista General de Derecho Público Comparado, Quito, v. 9, p. 1- 24, set. 2011.

SANTOS, Boaventura de Sousa. La reinvención del Estado y el Estado plurinacional. Osal. Santa Cruz de la Sierra, Bolivia: Kipus, 2007.

SANTOS, Boaventura de Sousa. Refundación del Estado en América Latina: Perspectivas desde una epistemología del Sur. Lima, Perú: Instituto Internacional de Derecho y Sociedad, 2010.

SIEYÈS, Emmanuel Joseph. A constituinte burguesa: que é o Terceiro Estado? 3. ed. Rio de Janeiro: Lumen Juris, 1997.

STRECK, Lenio Luiz; MORAIS, José Luis Bolzan de. Ciência politica e teoria geral do Estado. 7. ed. Porto Alegre: Livraria do Advogado, 2012. 
TAPIA, Luis. Una reflexión sobre la idea de Estado plurinacional. Clacso, Buenos Aires, v. 22, n. 8, p. 47-63, set. 2007.

VARGAS, Idón Moisés Chivi. Constitucionalismo emancipatorio y desarrollo normativo: Desafíos de la asamblea legislativa plurinacional. Bolívia, 2009. (mimeo).

V. GARCÉS, Fernando. Os esforços de construção descolonizada de um Estado plurinacional na Bolívia e os riscos de vestir o mesmo cavalheiro com um novo paletó. In: VERDUM, Ricardo (Org.). Constituição e Reformas Políticas na América Latina. Brasília: Inesc, 2009. p. 167-192.

VILLORO, Luis. Estado plural, pluralidad de las culturas. Barcelona: Paidós, 1997.

WOLKMER, Antonio Carlos. Constitucionalismo latino-americano. Tendências contemporâneas. Curitiba: Juruá, 2013.

WOLKMER, Antonio Carlos. Pluralismo jurídico: fundamentos de uma nova cultural no Direito. 3. ed. São Paulo: Alfa-Ômega, 2001.

WOLKMER, Antonio Carlos; MACHADO, Lucas. Para um novo paradigma do Estado plurinacional na América Latina. Novos Estudos Jurídicos, versão eletrônica, v. 18, 2013. Disponível em: <www.univali.br/periodicos>. Acesso em: 19 out. 2016.

YAPUR, Fernando L. García. Nuevo constitucionalismo y descolonización en la Constitución Política de Bolivia. In: VARGAS, Idón Moisés Chivi (Org.). Bolivia - Nueva Constitución Política del Estado: conceptos elementales para su desarrollo normativo. La Paz, Bolivia: Vicepresidencia del Estado Plurinacional, 2010. p. 167-180. 